\title{
SOBRE LA ESTRUCTURA DISCURSIVA DE LA ORACIÓN Y SU PROYECCIÓN SINTÁCTICA: EL CASO DE LOS ADVERBIOS ORACIONALES Y OTROS CONSTITUYENTES DE LA PERIFERIA ORACIONAL ${ }^{\prime}$
}

\author{
Teresa María Rodríguez Ramalle \\ Universidad Complutense de Madrid. Grupo DIME \\ teresaramalle@ccinf.ucm.es
}

\begin{abstract}
Resumen
En este trabajo voy a investigar la relación que existe entre las categorías funcionales extendidas de la oración vinculadas con la estructura discursiva (Speas y Tenny, 2003) y ciertos constituyentes con alcance oracional y cuya interpretación remite necesariamente a aspectos discursivos. Los constituyentes de los que me ocuparé van a ser adverbios de dominio o punto de vista, adverbios orientados al hablante modificadores de la manera del decir y la conjunción que con valor enunciativo, capaz de introducir el discurso. Estos tres elementos, aparentemente tan dispares, tienen en común su ubicación en el margen izquierdo de la oración y la presencia en su interpretación de dos factores: los relacionados con las propiedades lingüísticas de las unidades léxicas y los que remiten a la información extralingüística y a los conocimientos compartidos por los hablantes.
\end{abstract}

PALABRAS CLAVE: adverbios de dominio, discurso, estructura funcional.

\begin{abstract}
In my paper I will analyze the relationship between the extended functional projections of the left periphery related to the discursive structure (Speas and Tenny, 2003) and some constituents that take scope over the sentence and whose interpretation depends on discursive aspects. The constituents I will study are the following: adverbs of point of view, sentence adverbs oriented to the speaker and the enunciative conjunction que. The three categories have some aspects in common: the three constituents are located on the left periphery positions of the sentence; besides they are interpreted according to their linguistics properties and to the discursive information and the knowledge of the speakers.
\end{abstract}

KEY WORDS: point of view adverbs, discourse, functional structure.

\section{Introducción}

Los adverbios oracionales inciden sobre toda la oración; es por ello por lo que estos adverbios se han vinculado con proyecciones alojadas en el margen preverbal de la oración y vinculadas directamente con la presencia del hablante como responsable directo de su habla.

1 Este trabajo forma parte de los estudios realizados dentro del proyecto investigador financiado por la Universidad Complutense de Madrid Ficción y discurso en prensa, dirigido por el doctor D. Joaquín Garrido (UCM) e integrado por miembros del grupo investigador El discurso en los medios de comunicación (interacción entre la lengua, estilos, tipología e historia de los géneros en los medios) de la Universidad Complutense de Madrid. 
Como adverbios que tienen alcance sobre el contenido de la oración y, a la vez, se vinculan con el hablante, son elementos capaces de establecer relaciones entre el contenido de la oración y el contexto lingüístico inmediato o extralingüístico. Precisamente el contexto, manifestado tanto en el discurso previo como en los conocimientos compartidos en un determinado momento por hablante y oyente, influye de manera determinante en el momento de interpretar ciertos adverbios y estructuras que se proyectan en el margen preverbal de la oración: adverbios de dominio, adverbios orientados al hablante y la conjunción que con valor enunciativo.

Los adverbios de dominio son un ejemplo interesante de relación entre las propiedades de alcance y la posición. Por adverbios de dominio nos referimos a aquellos que establecen ámbitos dentro de los que interpretar una oración o un adjetivo -si la incidencia es adjetival-. Como veremos, las bases adjetivas que intervienen en la formación de tales adverbios también crean dominio o ámbitos; sin embargo, el cambio categorial de adjetivo a adverbio permite ampliar las posibilidades de alcance del adverbio resultante, pues de incidir sobre un nombre puede llegar a tener alcance sobre toda una oración y, en relación con este aspecto, también permite incluir rasgos discursivos en la interpretación final de la relación entre el adverbio de dominio y los constituyentes a los que modifica dicho adverbio. La relación con la periferia oracional es la que, de acuerdo con nuestra propuesta, posibilita la presencia de factores extraligüísticos en la interpretación del adverbio de dominio. A partir de esta hipótesis también se puede analizar el comportamiento de otros constituyentes y categorías vinculadas con la periferia oracional y que, en cuanto a su interpretación, también se ven influidos por la información de tipo extralingüístico: nos referimos a los adverbios orientados al hablante y modificadores de la manera de hablar y a la conjunción que como introductora del discurso. En este trabajo se revisarán el comportamiento sintáctico y la interpretación que reciben los adverbios de dominio, los adverbios orientados al hablante de la manera de hablar y la conjunción que con valor enunciativo.

La organización de este artículo es la siguiente: tras esta introducción, en la segunda sección (Los adverbios oracionales y la periferia oracional) haremos un breve repaso por los conocimientos que se tienen sobre la relación entre las proyecciones funcionales propuestas hasta este momento en el margen izquierdo de la oración y los adverbios oracionales que se han generado en dicha posición. En la tercera sección (Los adverbios de dominio) estudiaremos las características lingüísticas y extralingüísticas que intervienen en la interpretación de tales unidades; para ello ofreceremos datos de una variedad de adverbios: económicamente, socialmente, moralmente, musicalmente y políticamente. A partir de las conclusiones extraídas en este apartado sección, en la sección cuarta (Los adverbios orientados al hablante) analizaremos el comportamiento de los adverbios sinceramente, francamente y honestamente cuando tienen alcance sobre toda la oración. En la sección quinta (La conjunción que enunciativa) repasaremos brevemente los principales valores de la conjunción que, prestando especial atención a aquellos en los que el valor de marca introductora del discurso desencadena determinados procesos sintácticos. En la sección 6 (La estructura funcional de la periferia izquierda de la oración), en primer lugar, expondremos las bases principales de la estructura funcional extendida que se propone con el fin de incluir aspectos discursivos, para, en segundo lugar, y partiendo de dicha estructura novedosa, dar cuenta de la posición sintáctica que ocupan los constituyentes estudiados. Comprobaremos, por ejemplo, que la presencia de la conjunción que unida a un verbo de habla y a un sujeto pospuesto nos da pistas acerca 
de la estructura funcional extendida de la oración. Por último, en la sección 7 (¿Qué ocurre en la modificación adjetiva?) trataremos brevemente de los usos en los que los adverbios de dominio modifican directamente a un adjetivo.

\section{Los adverbios oracionales y la periferia oracional}

Los adverbios oracionales han sido caracterizados ampliamente en diferentes trabajos (Hernanz y Brucart 1987, Rodríguez Ramalle, 1999 y 2003). Son constituyentes parentéticos, pues van entre pausas y pueden ocupar diferentes posiciones en la oración; además, no se ven afectados por restricciones relativas a la clase de acción verbal: Francamente, María pesa cincuenta kilos y Lamentablemente, Luis no sabe ruso. La modificación de estos adverbios puede abarcar la expresión de las diversas modalidades: \{Probablemente /seguramente\}, todo ha terminado ya, el juicio por parte del hablante ante lo ocurrido: \{Felizmente / lamentablemente\}, todo ha terminado ya, o la manera en que el hablante se sitúa ante lo que dice: \{Brevemente / honestamente\} todo ha terminado ya. En los dos primeros casos, es posible parafrasear el adverbio mediante una estructura copulativa en la que la base adjetiva del adverbio actúa como predicado: 'Es probable o lamentable que...'; en el último ejemplo, el adverbio de la manera del decir puede ser sustituido por un adverbio modificador de un verbo de habla implícito: 'Te digo brevemente que...', o por un adverbio modificador del sujeto y de la acción que realiza: 'Soy honesto al decirte que...'. De entre todas estas clases, los adverbios de la manera del decir, también denominados orientados al hablante, son los que tienen un alcance mayor, pues son independientes de la modalidad oracional. Una prueba de ello reside en que pueden situarse delante de la interrogación, lo que no es posible con el resto de adverbios oracionales:

(1) a. Sinceramente, ¿aguantas a Juan?

b. Francamente, ¿te sentó mal la broma?

(2) a. *Posiblemente, ¿estás bien?

b. *Lamentablemente, ¿se ha terminado ya?

En diferentes trabajos (Rizzi, 1997; Cinque, 1999; Belletti, 2004) se ha propuesto ampliar la estructura de la oración con el fin de reflejar de la manera más precisa posible los fenómenos que afectan a los constituyentes con dominio oracional, entre ellos los adverbios. El objetivo último de estos estudios es el de expresar la relación entre la interpretación y la posición sintáctica, de modo que la primera se derive de la configuración del margen preverbal. Así, procesos tales como la topicalización, la focalización y la interpretación de las diferentes clases de adverbios se explican a partir de su ubicación en diferentes categorías funcionales especializadas en dichos contenidos. Un ejemplo de estas nuevas proyecciones funcionales lo encontramos en Rizzi (1997 y 2004). En el primer estudio se parte de la idea de que el Sintagma Complementante, asociado con la modalidad, se divide en diferentes proyecciones funcionales. En primer lugar, tenemos una proyección Sintagma Fuerza (Force Phrase), categoría que ocupa la posición jerárquicamente superior dentro del margen preverbal de la oración y que está asociada, entre otras cosas, con la expresión de la fuerza ilocutiva. Los tópicos múltiples: A Juan, ayer, lo vi haciendo cola en la puerta del teatro se generan como especificadores de una proyección Sintagma Tópico múltiple que toma como 
complemento una proyección Sintagma Complementante, caracterizada por proyectar una posición de especificador por la que compiten los operadores interrogativos, los focos y los tópicos únicos preverbales. En un trabajo más reciente, Rizzi (2004) retoma su propuesta del modo siguiente:

\section{(3) [SFuerza [STópico [SInt [SFoco ]]]]}

El Sintagma Interrogativo estaría destinado a los pronombres interrogativos no argumentales, que, por ejemplo, en español presentan unos rasgos particulares, pues no requieren inversión del verbo: ¿Por qué Juan dice eso ahora? El Sintagma Foco se correspondería con el Sintagma Complementante, pues, dada la incompatibilidad entre preguntas y focos contrastivos, ambos elementos se relacionan con una misma posición: LUIS me llamó ayer (y no Pedro), ¿Quién llamó ayer?

Dado que los adverbios de la manera del decir ocupan una posición en la oración desde la que tienen alcance sobre el resto de adverbios, así como sobre los operadores interrogativos, en Rodríguez Ramalle (2003 y 2005) se propone que tales adverbios se sitúen en la proyección funcional que ocupa la posición jerárquicamente superior dentro del margen preverbal de la oración y que está vinculada con la expresión de la fuerza ilocutiva: dicha categoría, como ya se ha dicho, recibe el nombre de Sintagma Fuerza (Force Phrase). Así pues, los adverbios de la manera del decir se generarían como especificadores múltiples de la proyección mencionada, situándose delante de los operadores interrogativos generados en el especificador del SComp. En esta posición se interpretan como operadores ilocutivos con alcance oracional.

En este trabajo partiremos de la idea de que los adverbios de la manera del decir y, en general, los adverbios oracionales y los constituyentes vinculados con la expresión de la manera de hablar se ubican en la periferia izquierda de la oración. En esta posición es predecible que en la interpretación de tales unidades no solo intervengan aspectos exclusivamente lingüísticos sino también otros factores que tienen que ver con el discurso en el que se inserta el adverbio o constituyente oracional, así como con aspectos relacionados con los conocimientos que tienen los hablantes acerca de la situación comunicativa.

\section{Los adverbios de dominio}

Los adverbios de dominio son adverbios oracionales, pues pueden ubicarse en cualquier posición dentro de la estructura oracional, siempre que vayan entre pausas; además, tienen alcance sobre toda la oración: La población de la zona, étnicamente, pertenece a pueblos minúsculos.

Los adverbios de dominio se utilizan productivamente en los medios de comunicación para establecer dominios dentro de los que interpretar las oraciones o los adjetivos sobre los que inciden:

(4) a. P. Ni Beatles ni Rolling Stones.

R. No, musicalmente no he sido muy aficionado a lo anglosajón. Lo mío es lo francés, la canción francesa, Brassens, Brel, Bécaud. [RAE: Banco de datos (CREA) Corpus de referencia del español actual. <http://www.rae.es> El País. Babelia, 22/03/2003] 
b. La actual alcaldesa, María del Carmen Guijorro (PP), calificó de «incoherente» el acuerdo de Gobierno entre PSOE e IU, ya que «se ha llamado sinvergüenzas, Tamayos, se han acusado de cohecho, se han interpuesto querellas criminales mutuamente... y ahora se meten en la misma cama, políticamente hablando, por la ambición de ocupar el sillón del poder». [RAE: Banco de datos (CREA) Corpus de referencia del español actual. <http:// www.rae.es> El País Digital, 2005]

Los adverbios musicalmente y políticamente que aparecen en las oraciones de (4) se caracterizan semánticamente por crear las condiciones pertinentes dentro de las cuales interpretar la oración sobre la que tienen alcance. Este tipo de adverbios domina, por tanto, a toda la oración, actuando como modificadores oracionales. Como vemos en el ejemplo de (4b), es posible encontrar secuencias en las que un adverbio de dominio aparece acompañado por un verbo de habla en gerundio. Toda la secuencia políticamente hablando se utiliza para matizar la afirmación contenida en la oración principal: 'Ahora se meten en la misma cama'. El hecho destacado es que el adverbio incide sobre la forma verbal en gerundio: 'hablando según un punto de vista político', pero modifica a toda la oración. Es por ello por lo que estos adverbios se han vinculado con proyecciones alojadas en el margen preverbal de la oración y vinculadas directamente con la presencia del hablante como responsable directo de su habla. Como adverbios que tienen alcance sobre el contenido de la oración y, a la vez, se vinculan con el hablante, figura que se puede manifestar a veces en la estructura sintáctica mediante otros procedimientos -por ejemplo, la conjunción que con valor enunciativo: Que digo yo que nos podríamos ir ya, como veremos más adelante- son elementos capaces de establecer relaciones entre el contenido de la oración y el contexto lingüístico o extralingüístico: conocimientos compartidos por hablante y oyente. Este tipo de información va a ser importante en el momento de interpretar tales adverbios.

Los adverbios de dominio no solo tienen alcance sobre toda la oración, sino que también pueden incidir sobre un adjetivo, estableciendo los límites de su interpretación:

(5) a. «Siempre fui de salir mucho a escuchar música, me ponía cerca de la cabina y me fijaba en lo que sonaba. En Bruselas salí mucho por las noches porque es una ciudad musicalmente muy fuerte. En México, como tenía más dinero, incluso viajaba como una vez al mes a Miami, e iba a las mejores fiestas por Costa Rica o Guatemala». [RAE: Banco de datos (CREA) Corpus de referencia del español actual. $<$ http://www.rae.es $>$ Radikal. Suplemento de La Opinión de Tenerife, 29/07/2004]

b. «En el teatro tenemos la ventaja de poder jugar con la reacción del público, es mucho más vivo, y tocar más tema», explicaba ayer More. Su compañera Belén Rubio era más precisa: «En el teatro no tenemos censura, o lo que ahora se llama lo políticamente correcto, que es censura al fin y al cabo. [RAE: Banco de datos (CREA) Corpus de referencia del español actual. <http://www.rae.es> El Diario Vasco, 23/01/2004]

En estos ejemplos, los adverbios musicalmente y políticamente inciden directamente en el adjetivo al que modifican. El adverbio denota, en este caso, el marco en el que debe interpretarse la propiedad denotada por el adjetivo.

En diversos trabajos (Rodríguez Ramalle, 1999 y 2003) se ha demostrado que los adverbios en -mente heredan las propiedades semánticas de sus bases adjetivas. Existen pruebas que demuestran que dichas bases se comportan como adjetivos relacionales: enseñanza 
musical, decisión política, etc., caracterizados por crear dominios o ámbitos dentro de los cuales interpretar los nombres a los que modifican (Bosque, 1993 y Demonte, 1999). En efecto, los adjetivos relacionales, modificadores de aspectos concretos de la estructura semántica de un nombre, dan lugar a adverbios de dominio, mientras que si tenemos adjetivos calificativos que dicen propiedades, el resultado será la formación de adverbios de manera verbal predicados de las acciones.

Los adjetivos relacionales presentan unas propiedades sintácticas y semánticas especiales. Si bien los adjetivos calificativos son graduables: muy alto, bastante interesante, los de relación no lo son, puesto que no denotan propiedades. Por este motivo, los adjetivos familiar y musical en los sintagmas reunión muy familiar y sonido muy musical sólo pueden interpretarse como calificativos, frente a los usos relacionales documentados en discusión familiar y publicación musical, en los que nunca cabría la posibilidad de graduar el adjetivo: *discusión muy familiar, *publicación muy musical.

El hecho de que los adjetivos relacionales no admitan modificadores de grado y requieran adyacencia estricta con el nombre al que modifican ha llevado a algunos autores a proponer que dichos adjetivos son, en realidad, categorías nominales más que adjetivales, que establecen un tipo de relación especial con el nombre al que acompañan, similar a la de una estructura apositiva N+N. Recientemente, Fábregas (2007), siguiendo esta línea, ha demostrado que los adjetivos relacionales son categorialmente nombres a los que se le ha añadido un sufijo adjetival, que, sin embargo, no otorga categoría a la base nominal a la que se une. Los adjetivos relacionales serían, por tanto, nombres que modifican a otros nombres.

Dado que los adjetivos relacionales tienen propiedades nominales, no debe extrañarnos encontrar ejemplos en los que tales adjetivos actúan como argumentos que reciben su papel temático del núcleo o predicado al que acompañan. Como vemos en los ejemplos de (6a y b), la interpretación de los adjetivos relacionales argumentales depende de la estructura temática del nombre:

(6) a. Construcción naval 'construcción de barcos'.

b. Viaje presidencial 'viaje del presidente'.

En cuanto a los ejemplos de (7a y b), si comparamos los sintagmas coche solar y central solar, es fácil comprobar que, en el primer caso, solar se refiere a lo que hace que el coche se mueva, mientras que en el segundo, solar simplemente denota el tipo de objeto producido por la central. La diferencia de interpretación reside, como ha puesto en evidencia recientemente Demonte (1999), en las especificaciones semánticas que contiene el propio nombre y que nos permiten saber, entre otras cosas, que un coche tiene como función principal la de desplazarse y transportar objetos o personas, mientras que un nombre como central es un productor; por este motivo, adjetivos como solar, nuclear, eléctrica, cuando acompañan a este nombre, hacen referencia al objeto producido por la central.

(7) a. Coche solar 'coche que se mueve por energía solar'.

b. Central eléctrica 'central que produce electricidad'. 
Los adverbios de dominio se relacionan con este segundo tipo de adjetivos, llamados clasificativos, pues comparten con éstos los mismos rasgos semánticos básicos, como vamos a demostrar a continuación. Fijémonos en los siguientes datos con el adverbio económicamente:

(8) a. Un marco que favorece a los equipos grandes, los económicamente fuertes, que podrán dejar a los pequeños sin sus figuras emergentes. [RAE: Banco de datos (CREA) Corpus de referencia del español actual. <http://www.rae.es $>$ El País, 09/12/2003]

b. La clase económicamente poderosa surgida en la segunda mitad del XIX gracias a la hegemonía del caucho brasileño podía haber invertido sus riquezas en otro tipo de actividades o signos de ostentación. [RAE: Banco de datos (CREA) Corpus de referencia del español actual. <http://www.rae.es> El País. Babelia, 24/04/2004]

c. «Es algo lógico económicamente porque el consumidor se queda mucho más tranquilo, es una prueba de voluntad de innovación y de mejora permanente y, por encima de todo, es algo bueno para el medioambiente, para el personal que trabaja en las viñas y para la comunidad en el seno de la cual vivimos», añade. [RAE: Banco de datos (CREA) Corpus de referencia del español actual. $<$ http://www.rae.es> El Mundo, 03/01/2003]

d. No tiene vida propia, primero porque económicamente está cercada por el marido, después, porque siempre hay algo más importante que atender que sus propias necesidades. [RAE: Banco de datos (CREA) Corpus de referencia del español actual. $<$ http://www.rae. es> Papeles del Psicólogo, nº 88, 05/08/2004]

La interpretación del adverbio en todos estos casos se ajusta a lo previsible: los rasgos contenidos en su base adjetiva. No importa el alcance que tenga, ni tampoco la posición que ocupe en la estructura sintáctica. Si nos fijamos en los datos de (8a y b), el adverbio de dominio tiene alcance sobre un adjetivo, al que se antepone. En ambos casos, el adverbio se debe interpretar a partir de las condiciones que impone el adjetivo; de este modo, interpretamos que los económicamente fuertes son 'los fuertes desde el punto de vista económico o en la economía', mientras que la clase económicamente poderosa se refiere a 'la clase poderosa en lo que respecta a los asuntos económicos'. En el ejemplo de (8c), el adverbio de dominio también modifica a un adjetivo, aunque en este caso, su posición va pospuesta. Lo interesante aquí es que el cambio de posición no influye de manera relevante, al menos en lo que nosotros podemos apreciar, en la interpretación básica de la relación adverbio-adjetivo, pues la paráfrasis de algo lógico económicamente sería 'algo lógico desde una perspectiva o punto de vista económico', similar como vemos, a las paráfrasis de los ejemplos de (8a y b). Como hemos señalado en el apartado 2., la característica básica de los adverbios con dominio oracional es su carácter de constituyentes parentéticos, que, en consecuencia, pueden insertarse en diferentes posiciones sin alterar su incidencia oracional. En su uso como modificadores dentro del dominio adjetival, los adverbios de dominio también pueden ocupar diferentes posiciones dentro de las categorías que proyecta el adjetivo, sin cambiar su interpretación.

Si nos fijamos en las propiedades de la base adjetiva relacional, comprobaremos que el adjetivo económico en secuencias como reunión económica, asuntos económicos o problema económico significa 'reunión relacionada con la economía', 'asuntos de tipo económico' o 'problema que tiene que ver con la economía': en los tres casos, económico presenta unos rasgos básicos que podemos parafrasear como 'relacionado con la economía', rasgos que también aparecen de manera decisiva en la paráfrasis de los adverbios de dominio correspondientes. 
Por último, el ejemplo de (8d) contiene un caso de adverbio de dominio con alcance oracional. En este ejemplo, la oración se interpreta según las condiciones impuestas por el adverbio, de modo que económicamente está cercada por el marido significa que 'está cercada por el marido en lo que respecta a los asuntos económicos'.

Hasta ahora nos movemos dentro de lo previsible: la interpretación del adverbio en diferentes dominios sintácticos depende de las propiedades derivadas de su base adjetiva. Esta apreciación, no obstante, debe ser matizada de dos maneras.

En primer lugar, fijémonos en que cuando se forma el adverbio de dominio, el sufijo amplía las posibilidades de modificación de la base a la que se aplica al incluir en su modificación características semánticas nuevas y no presentes, en principio, en la base derivativa (véase, por ejemplo, Fábregas, 2007 en su estudio sobre los adjetivos relacionales). Ante todo, el sufijo - mente implica un cambio categorial: de adjetivo a adverbio. Pero este cambio categorial conlleva además una ampliación de las posibilidades de modificación de la base adjetiva, pues de ser un complemento dentro del dominio del SN pasa a convertirse en un modificador que puede llegar a incidir sobre toda una oración. Este proceso va unido también a un cambio en la interpretación de la relación entre adverbio y modificado, pues en la relación semántica entre el adverbio de dominio y las categorías a las que modifica pueden aparecer rasgos interpretativos que dependen del contexto extralingüístico, de modo que las características denotadas por un adjetivo deben ser valoradas a partir de criterios extralingüísticos. De este modo, cualquier categoría modificada por un adverbio de dominio debe ser interpretada a partir de las condiciones semánticas impuestas por el propio adverbio y que derivan de los rasgos lingüísticos heredados de la base adjetiva relacional, así como de las condiciones extralingüísticas que adquiere el adverbio en el proceso de derivación.

Partiendo de esta nueva hipótesis, analicemos ahora el caso del adverbio socialmente:

(9) a. Pocos meses antes de morir, en un almuerzo en mi casa, Don Juan se lamentaba del espectáculo de las bodas reales en Europa y vaticinaba la quiebra de las viejas monarquías democráticas que se encuentran entre los países políticamente más libres del mundo, socialmente más justos, económicamente más desarrollados, culturalmente más progresistas. [RAE: Banco de datos (CREA) Corpus de referencia del español actual. <http://www.rae.es> La Razón Digital, 01/04/2003]

b. Campell habla de los individuos con una conducta que plantea discordancias con la religión oficial, bien por irreligiosidad, bien por practicar otro culto, como «socialmente aislados» y susceptibles, por lo tanto, de marginación. [RAE: Banco de datos (CREA) Corpus de referencia del español actual. $<$ http://www.rae.es $>$ Hispania Nova. Revista de Historia Contemporánea, $\mathrm{n}^{\circ} 3,2003$ ]

c. - ¿Por qué nos atrae el éxito?

- Porque detrás hay una idea implícita de felicidad.

- ¿Y socialmente creemos que se cumple eso de «a quien buen árbol se arrima...»? [RAE: Banco de datos (CREA) Corpus de referencia del español actual.http://www.rae. es $A B C, 03 / 11 / 2004]$

En (9a y b), el adverbio de dominio determina la interpretación del sintagma al que acompaña a partir de los rasgos semánticos heredados de su base adjetiva: 'más libre en lo que respecta a la política, más justo desde un punto de vista social, más progresista en el nivel cultural', 'aislados desde el punto de vista social, en la sociedad'. En el ejemplo de (9c), el 
adverbio socialmente tiene alcance sobre toda la oración, pero su interpretación sigue tomando como punto de partida los rasgos contenidos en su base adjetiva relacional. Una paráfrasis posible de la pregunta: ¿Y socialmente creemos que se cumple eso de «a quien buen árbol se arrima...»? sería ‘¿creemos que se cumple eso a nivel social o en la sociedad?'. Sin embargo, en los siguientes ejemplos, también con el adverbio socialmente, observamos diferencias importantes:

(10) a. No entiendo ese empeño en que gays y lesbianas se comporten de una manera socialmente mejor vista. Es como el desfasado empeño feminista de compararse a los hombres y pretender ser como ellos, como si no tuviéramos bastante con los que hay. [RAE: Banco de datos (CREA) Corpus de referencia del español actual. $<$ http://www. rae.es> El País. El País de las Tentaciones, 10/01/2003]

b. En abril de 2001 culminaron la primera fase del trabajo, consistente en la recogida de datos y elaboración de las correspondientes memorias de investigación. En este momento se encuentran en la segunda fase, la de creación de un conjunto de materiales de prevención y ayuda a educadores que quieren diseminar, este año, en el territorio de la Unión Europea. Los recursos son cuatro: un disco compacto para su difusión masiva, una serie de páginas web donde se agruparán los conocimientos, materiales escritos con consejos y propuestas (trípticos, carteles...), y lo que sus artífices consideran la joya de la corona: un observatorio virtual permanente que, con el nombre de OFSI (Observatory for Safer Internet), «proporcionará acceso a todo tipo de información que contribuya a hacer un uso socialmente responsable de Internet», según Angulo. [RAE: Banco de datos (CREA) Corpus de referencia del español actual. $<$ http://www. rae.es> El País. Ciberpaís, 20/03/2003]

En (10a), la interpretación básica que adquiere el sintagma mejor vista depende de los rasgos: 'en la sociedad o desde un punto de vista social'. Así, el significado que incorpora el adverbio se puede predecir a partir del significado de su baje adjetiva. En consecuencia, el sintagma se comporten de una manera socialmente mejor vista significa 'comportarse de una manera mejor vista en la sociedad o desde un punto de vista social'. Nótese, sin embargo, que en la interpretación final que recibe el adverbio socialmente en relación con el sintagma mejor vista aparecen ideas o conceptos que forman parte de los conocimientos que los hablantes y oyentes poseen acerca de lo que se considera 'socialmente bien visto', a saber: discreto, sin provocaciones, que se ajusta a lo tradicional, etc. Si esto es cierto, entonces, el entorno favorece la presencia de unos rasgos extralingüísticos que inciden en el sentido final de la relación adverbio-adjetivo.

Fijémonos ahora en la oración de (10b). En (10b) se requiere que el oyente busque las condiciones interpretativas que no se derivan directamente del significado de la base adjetiva. El sintagma socialmente responsable, recogido aquí, no significa 'reponsable desde el punto de vista social, o en la sociedad'. La interpretación de socialmente responsable es 'responsable de acuerdo con unas normas sociales o según lo que la sociedad espera del concepto de responsabilidad'; dichas normas deben ser rellenadas por el propio oyente según su conocimiento de la realidad. Socialmente responsable aquí puede significar 'que produzca beneficios a la sociedad' o que 'contribuya a mejorar la sociedad'. Esta nueva lectura surge, seguramente, de la relación que existe hoy en día entre un uso irresponsable de Internet, que produce consecuencias indeseables, y el uso responsable, que siempre debe ser potenciado. 
El uso socialmente responsable de Internet es, por tanto, el que se opone a esas consecuencias perjudiciales.

Según lo dicho, un sufijo puede hacer que la base sobre la que se aplica incluya en sus posibilidades de modificación características semánticas no presentes, en principio, en la base de derivación. En el caso de los adverbios de dominio se ha demostrado que el sufijo permite que el adverbio en -mente determine la interpretación del adjetivo al que modifica a partir de características semánticas relacionadas con los conocimientos compartidos por hablante y oyente, y que pueden verse realizados en el discurso. El hecho de que tengamos un adverbio de dominio con posibilidad de tener alcance sobre diferentes constituyentes oracionales y de situarse en la periferia de la oración o del adjetivo sobre el que incide, sin duda, permite que éste pueda admitir la presencia de rasgos interpretativos que no se pueden predecir exclusivamente a partir de propiedades lingüísticas, pues tienen que ver también con los conocimientos compartidos por hablante y oyente. En definitiva, es la relación con la periferia oracional la que, en nuestra opinión, posibilita la presencia de factores extraligüísticos en la interpretación del adverbio de dominio. La presencia de estos factores no es un hecho aislado u ocasional; a continuación se muestran más ejemplos con los adverbios moralmente, musicalmente y políticamente.

El adverbio moralmente también nos ofrece datos interesantes.

(11) a. El terrorismo es enemigo de nuestra democracia. Ni política y menos aún moralmente puede justificarse la vinculación de cualquier organización social y política con el terrorismo. [RAE: Banco de datos (CREA) Corpus de referencia del español actual. $<$ http://www.rae.es> El Norte de Castilla, 15/06/2002]

b. El tercer comunicado, en diciembre pasado, redactado tras la decisión de la caja de adherirse a la Ley Financiera y pasar a la supervisión del Ministerio de Economía fue mucho más contundente y evidenció la crisis: Martínez tildó de «escandalosa» la póliza millonaria, tachó de «moralmente reprobables» los comportamientos de Castillejo, le acusó de llegar a «pactos» con el PP y criticó que «unos sacerdotes sean ejecutivos de una empresa financiera». [RAE: Banco de datos (CREA) Corpus de referencia del español actual. $<$ http://www.rae.es> El País, 17/03/2003]

c. «El dolo puede ser reprochable moralmente, en mayor medida, a la que era su esposa, pero jurídicamente lo es a los dos por igual», señala la sentencia, de la que ha sido ponente la magistrada Carmen Escrig. [REA: Banco de datos (CREA) Corpus de referencia del español actual. $<$ http://www.rae.es $>$ ABC, 17/12/2004]

En los ejemplos propuestos, el adverbio se interpreta de manera constante a partir de los rasgos contenidos en el adjetivo relacional moral: 'la violencia no puede justificarse según las normas morales', 'reprobable en cuanto a la moralidad o lo moral', 'reprochabe en lo que respecta a la moralidad o según las reglas morales'. Como se puede observar, el cambio de alcance o de posición incide únicamente en el tipo de constituyentes sobre los que se deben aplicar las condiciones impuestas por el adverbio de dominio a partir de su base adjetiva, pero no influye en la interpretación. Existen ejemplos en los que este mismo adverbio se sitúa en un contexto que interviene decisivamente en la interpretación que recibe y, en consecuencia, en el significado que adoptan los constituyentes a los que modifica. Fijémonos en ejemplos como los siguientes: 
(12) a. El arzobispo de Gales, Rowan Williams, candidato favorito para suceder al arzobispo de Canterbury como primado de la Iglesia anglicana, critica duramente la ofensiva aliada sobre Afganistán en un libro titulado «Escribiendo en el polvo». Según él, la campaña encabezada por Estados Unidos contra el país asiático, está «contaminada moralmente» y considera que los bombardeos han perdido credibilidad y son moralmente equivalentes al terrorismo que pretenden combatir. [RAE: Banco de datos (CREA) Corpus de referencia del español actual. <http://www.rae.es> La Razón, 21/01/2002]

b. Creemos, finalmente, que es cínico e inmoral que se destruya un país para desarmar a un dictador, mientras las grandes potencias continúan fabricando y traficando con armas. Hay que recordar que EE UU representa el 36\% del gasto mundial de armamentos y el Reino Unido es el segundo exportador mundial de armas. En un mundo donde mueren dos millones de personas al año por enfermedades diarreicas infecciosas originadas por la falta de condiciones sanitarias adecuadas, el gasto militar de las grandes potencias es moralmente vergonzoso y es hoy la principal amenaza para la paz y el bienestar de la población mundial. [REA: Banco de datos (CREA) Corpus de referencia del español actual. <http://www.rae.es> El País. Salud, 18/02/2003]

En la oración de (12a) encontramos dos apariciones del adverbio moralmente. En el primer caso: la campaña encabezada por Estados Unidos contra el país asiático está «contaminada moralmente», contaminada moralmente se puede interpretar, siguiendo el requisito de la base adjetiva, como 'contaminada en lo que respecta a lo moral, a las reglas morales'. Pero el contexto en que se sitúa este sintagma, la guerra de Afganistán, junto con los conocimientos del lector-receptor nos permiten fijar mucho mejor qué es eso de 'lo moral': no es simplemente un tipo de comportamiento que se ajusta a las reglas morales. Aquí 'lo moral' significa lo que no tiene justificación, lo que no se ajusta a derecho, etc. En la segunda aparición del adverbio: los bombardeos han perdido credibilidad y son moralmente equivalentes al terrorismo que pretenden combatir, moralmente posee los rasgos que se deducen del contexto anterior: lo no ajustado a la legalidad. El adverbio no significa lo que está de acuerdo con lo moral o las reglas morales, sino todo lo contrario, pues moralmente aparece en una oración en la que se igualan los bombardeos y el terrorismo.

Fijémonos ahora en el dato de (12b). Aquí tenemos la secuencia: el gasto militar de las grandes potencias es moralmente vergonzoso y es hoy la principal amenaza para la paz y el bienestar de la población mundial. ¿Cuál es la interpretación que recibe aquí el adjetivo vergonzoso cuando aparece acompañado por el adverbio moralmente? No se está hablando únicamente de que 'el gasto militar sea algo vergonzoso para la moralidad', sino que 'es vergonzoso porque va en contra de la moralidad' y, como se nos dice en el propio discurso, ir en contra de lo moral, de las reglas o normas morales implica 'una amenaza para la paz y el bienestar de la población mundial'. En este ejemplo, por tanto, la relación adverbio-adjetivo no se apoya en lo establecido en la base adjetiva: 'vergonzoso según lo moral o las reglas morales', pues el propio discurso y los conocimientos que tienen los hablantes sobre el tema ayudan a fijar el contenido de 'lo moral', que es aquí aquello que va en contra de la paz, el bienestar, la justicia, etc. En la interpretación, se parte, por tanto, de unas guías básicas, las propiamente lingüísticas, las establecidas por la base adjetiva relacional moral, para, a partir de ellas, y con la ayuda, por una parte, del propio contexto discursivo y, por otra, de los conocimientos 
compartidos por los hablantes, establecer unas pautas de significado que van más allá de las fijadas por el adjetivo y que tienen que ver con la estructura discursiva y extralingüística.

En estos ejemplos hemos visto, por tanto, que el adverbio moralmente puede llegar a adquirir valores incluso opuestos a los que establece su base adjetiva, derivados del contexto en el que se inserta y de los conocimientos de los hablantes-lectores. Veamos otros casos parecidos.

El adverbio musicalmente posee una doble interpretación similar:

(13) a. P. Ni Beatles ni Rolling Stones.

R. No, musicalmente no he sido muy aficionado a lo anglosajón. Lo mío es lo francés, la canción francesa, Brassens, Brel, Bécaud. [RAE: Banco de datos (CREA) Corpus de referencia del español actual. <http://www.rae.es> El País. Babelia, 22/03/2003] b. ¿No cree que de esa manera podríamos dejarnos llevar y hacer concesiones al público? Es tu propia responsabilidad ser correcto musicalmente. Puede que haya gente que no tenga este sentido de responsabilidad, y si a la audiencia le gusta, es su propia decisión. [RAE: Banco de datos (CREA) Corpus de referencia del español actual. http:// www.rae.es Filomúsica, no 11,12/2000]

Mientras que en (13a), el adverbio musicalmente parece determinar la interpretación del sintagma al que acompañan a partir de los rasgos semánticos heredados de su base adjetiva: 'no he sido muy aficionado a lo anglosajón desde un punto de vista musical', en el ejemplo de (13b), el adverbio musicalmente requiere que el oyente se fije en condiciones que no aparecen directamente en el significado del adjetivo base musical. Ser correcto musicalmente no equivale aquí a ser 'correcto en cuanto a las reglas de la música'. En este fragmento, en el que se habla de responsabilidad ante el público, la corrección musical no se apoya en seguir las normas musicales, sino que parece exigir otros rasgos no contenidos en el adjetivo y presentes en el contexto y, seguramente, en los conocimientos de los hablantes. Musicalmente se puede referir a algo 'armónico, ajustado, proporcionado, incluso fiel a la música'. Desde este punto de vista, el sintagma pasaría a adquirir el valor de 'ser fiel, ajustado a tu propio valor o creencia musical'.

He dejado para el final, tal vez, el ejemplo más característico y conocido de interpretación basada en el contexto: el caso de la colación políticamente correcto/a (Rodríguez Ramalle, en prensa).

En el caso del adverbio políticamente, decimos que 'algo es bueno, adecuado conforme a unas reglas marcadas por lo político', donde políticamente crea las condiciones en las que se debe interpretar la propiedad denotada por el adjetivo. Dentro de estas condiciones se pueden incluir factores de significado que forman parte de la estructura conceptual del adjetivo, así como otros de carácter extralingüístico, que tienen que ver con los rasgos que añadimos al significado del adverbio políticamente según el entorno social. Estos segundos factores son determinantes en la relación entre políticamente y correcto, pues se ha constituido en un sintagma cada vez más utilizado y que no tiene un sentido fijo, sino que cambia en función del contexto. Con esto queremos decir que, en la colocación políticamente correcto, los rasgos que adquiere el adjetivo político al añadirle el sufijo adverbial están determinados por el conocimiento que tiene el hablante de la realidad. Ese bagaje le hace interpretar las propiedades denotadas por el adjetivo correcto a partir de unos rasgos variables: pueden ser equivalentes 
a 'democrático, adecuado, no provocativo, conciliador, que excluye lo negativo', como se ve en (14):

(14) a. El error de las personas que, en aras de lo políticamente correcto, aceptan la legalización del matrimonio entre personas del mismo sexo es que piensan que es algo que no va con ellos; no van a usarlo. [RAE: Banco de datos (CREA) Corpus de referencia del español actual. < $<$ ttp://www.rae.es> El País, 27/10/2004]

b. La emergencia de la figura de Fortuyn en el paisaje político y su asesinato a pocos días de unas elecciones legislativas en las que, según los sondeos, hubiera sacado un resultado espectacular, provocaron una conmoción en la sociedad holandesa, donde hasta entonces los políticos mantenían un discurso «políticamente correcto» que excluía referencias negativas respecto de la inmigración, la integración o la criminalidad. [RAE: Banco de datos (CREA) Corpus de referencia del español actual. $<$ http://www. rae.es> ABC, 03/11/2004]

Pero la colocación políticamente correcto puede significar lo opuesto a lo cierto: esta lectura la deducimos del contexto inmediato en el que se inserta el adverbio y que debe ser interpretado por los hablantes. En efecto, también puede tener valores negativos, como 'falto de libertad de expresión, no verdadero', como vemos en los siguientes ejemplos:

(15) a. Autor de varias monografías excelentes sobre la guerra civil, mi colega de Estados Unidos me comentó su pena por el rumbo que había tomado la historiografía española desde los años ochenta. «En lugar de historiar», me dijo, «se han dedicado a crear una versión políticamente correcta de la guerra civil española que no se corresponde con la realidad». [RAE: Banco de datos (CREA) Corpus de referencia del español actual. $<$ http://www.rae.es> La Razón, 24/03/2004].

b. Diván el terrible, realizada en coproducción con Teatro de las Maravillas, es un trabajo irónico y divertido, una crítica a una sociedad que se nos vende llena de libertades y que a su vez son coartadas por las reglas de lo políticamente correcto o disfrazadas con expresiones semánticas. Su protagonista, Simón, es un hombre que tras una vida llena de esfuerzos se encuentra impotente al ver que nada ha cambiado. [RAE: Banco de datos (CREA) Corpus de referencia del español actual. $<$ http://www.rae.es $>$ Artez. Revista de Artes Escénicas, nº 91, 01/11/2004].

Estos nuevos rasgos interpretativos tienen que ver con los factores que añadimos al adverbio políticamente según el contexto en el que se sitúa y nuestro conocimiento de la realidad social.

En definitiva, en la interpretación de los adverbios de dominio intervienen factores predecibles a partir de las propiedades semánticas de la base adjetiva, pero también hemos visto que aparecen otros factores que tienen que ver con los conocimientos de los hablantes acerca de la realidad, así como con el discurso en el que se inserta dicho adverbio. Este no es un caso extraño, pues hay más ejemplos en los que la influencia de los aspectos discursivos influye en la interpretación de los constituyentes relacionados con la periferia izquierda de la oración. Vamos a revisar a continuación otros casos en los que la posición en el margen preverbal y la interpretación también son dos aspectos íntimamente relacionados. 


\section{Los adverbios orientados al hablante}

La interpretación que reciben los adverbios orientados al hablante de la manera del decir y sus diferentes lecturas dependen, al igual que hemos visto con los adverbios de dominio, de las propiedades de las bases adjetivas, pero también de otras factores relacionados con los conocimientos compartidos por los hablantes y con el discurso inmediato.

Los adverbios y expresiones de la manera del decir, como sinceramente, francamente y honestamente en las oraciones de (16), se pueden definir por poner en relación el acto de habla con el sujeto o responsable que lo realiza. Fijémonos en los siguientes datos:

(16) a Según explicó la artista en entrevista telefónica con ESCENARIO, «no sé cómo lo logré, bueno creo que por el equipo de trabajo, pero sinceramente me sentía muy mal. El viernes mi doctor fue a verme al teatro y me puso una inyección. Al finalizar la función me dijo que tenía que irme para el hospital (San Pablo) porque estaba deshidratada y allí pasé la noche». [RAE: Banco de datos (CREA) Corpus de referencia del español actual. <http://www.rae.es> El Vocero de Puerto Rico, 10/06/2002].

b. «No puedo entender, francamente, por qué ha tomado tanto tiempo decidir si hay jurisdicción federal y el mandamus. Me parece que bajo las circunstancias, tres semanas es demasiado tiempo, demasiado tiempo», dijo Torruella ayer en la vista. [RAE: Banco de datos (CREA) Corpus de referencia del español actual. $<$ http://www.rae.es $>$ El Nuevo Día, 14/12/2004]

c. Si me eligen lo voy a asumir con mucho gusto para gratificar de algún modo la confianza que los electores han puesto en mí», dice la joven de apenas 19 años de edad e instructora de la Federación de Mujeres Cubanas en el territorio. «Y yo quisiera tener la edad de mi hija -comenta Neida- para poder hacer más, pero honestamente no le tengo miedo a la tarea.» [RAE: Banco de datos (CREA) Corpus de referencia del español actual. <http://www.rae.es> Granma, 21/10/2002]

En diferentes trabajos (véase por ejemplo Rodríguez Ramalle, 2003) se demuestra que los adjetivos que aparecen como bases en este tipo de adverbios se predican de los individuos en relación con la acción que estos realizan; esto es, adjetivos como franco, sincero, honesto pueden llegar a expresar una propiedad de la acción que realiza un individuo. Estas bases adjetivas intervienen también en la formación de adverbios modificadores de la manera verbal, en casos como los siguientes:

(17) a. Acertemos en las prioridades y logremos compartir un presupuesto. A estas dos conclusiones llegaba el alcalde Odón Elorza en un artículo que titulaba El presupuesto como espejo del Alma. Vayamos a ello. Creo sinceramente que en esta ocasión no va a haber ningún problema para que acertemos, como a usted le gusta decir, en que la prioridad para los donostiarras, además de alcanzar la tan ansiada libertad para quienes carecen de ella, es que se construya el mayor número de viviendas posible. ¿Estamos de acuerdo, señor Elorza? [RAE: Banco de datos (CREA) Corpus de referencia del español actual. $<$ http://www.rae.es $>$ El Diario Vasco, 23/01/2004]

b. Las dos comisiones mencionadas antes trabajaron a conciencia y advirtieron que ni siquiera ellas pudieron ponerse de acuerdo en todos los detalles. A pesar de eso pudieron hablar muy clara y francamente. Los resultados que dieron no son, por supuesto, para halagar a todo el mundo, sino lo contrario, pero cumplieron con el encargo que 
se les hizo. [RAE: Banco de datos (CREA) Corpus de referencia del español actual. $<$ http://www.rae.es> El Heraldo Digital, 25/10/2002]

c. A las personas con discapacidad no se las debería ayudar sólo en su día, sino los 365 días del año. Estas personas, entre bebés, niños, jóvenes y adultos, son dignos de admirar. Conozco a muchos ciegos que se ganan la vida trabajando honestamente. También recuerdo que los medios de comunicación resaltaron el esfuerzo de un joven, que salió de bachiller y que ahora es profesor de computación. Ellos son personas iguales y hasta mejores que nosotros porque saben amar, trabajar y luchan por romper los obstáculos que se les presenta. [RAE: Banco de datos (CREA) Corpus de referencia del español actual. <http://www.rae.es> El Deber, 18/10/2004]

En estos ejemplos, los adverbios son modificadores del verbo principal; así, se pueden parafrasear, respectivamente, del modo siguiente: 'yo creo de manera sincera que en esta ocasión no va a haber ningún problema', 'ellos pudieron hablar de manera clara y franca', 'muchos se ganan la vida trabajando de manera honesta'. En todos los ejemplos, el individuo del que se predica la propiedad denotada por el adjetivo es el sujeto de la oración, mientras que la acción que realiza está determinada por la predicación principal. Estas mismas bases adjetivas pueden formar adverbios orientados al hablante cuando el individuo se refiere al hablante como responsable de su discurso, mientras que la acción que realiza es el hecho mismo de hablar. Así, volviendo a los ejemplos de (16), comprobamos que en todos ellos el sujeto que habla es también el sujeto de la base adjetiva; por su parte, la acción que ejerce dicho sujeto siempre tiene que ver con el acto de hablar. En (16a), por ejemplo, se nos dice que el sujeto es sincero al decir que 'se sentía muy mal'. En el caso de (16b), el sujeto es franco cuando dice que 'no puede entenderlo'. Por último, en (16c), el sujeto es honesto cuando afirma que "no le tiene miedo a la tarea'?

Los datos evidencian que la lectura y orientación de los adverbios de la manera del decir dependen del hecho mismo de hablar y de la presencia del hablante como responsable de su habla. En los siguientes ejemplos, sin embargo, es posible encontrar un elemento nuevo que se debe tener en cuenta en la interpretación de estos adverbios:

(18) a. El vicepresidente puso en duda que se puedan superar algunas diferencias importantes que buena parte de la sociedad tiene con algunos sectores de la izquierda nacional. Preguntó: «¿Cuál es la posición colectiva y mayoritaria de los uruguayos respecto al capital extranjero? ¿Y cuál respecto a las empresas extranjeras? ¿Podemos pensar ingresar en el mundo y en un programa de inversión si le tenemos hostilidad al capital? Yo creo que no, francamente creo que no. Creo que es una discusión que los uruguayos aún nos debemos a la interna».[RAE: Banco de datos (CREA) Corpus de referencia del español actual. <http://www.rae.es> El País, 05/11/2002]

b. La voz del doctor Alfredo Cahe suena preocupada: «Todo esto que está pasando es desprolijo y va en desmedro del tratamiento de Diego. El ya tendría que estar en una comunidad cerrada. Pero va y viene de la clínica y, honestamente, yo tengo mis temores... porque estamos en tierra de nadie. Y esta es la última oportunidad que tenemos».

2 El individuo del que se puede predicar un adverbio orientado de la manera del decir puede ser también el oyente; esto es lo que ocurre cuando estos adverbios acompañan a oraciones interrogativas:

(i) a.Sinceramente, ¿te apetece venir?

b.Sé sincero (tú) al responderme si te apetece venir 
[RAE: Banco de datos (CREA) Corpus de referencia del español actual. $<$ http://www. rae.es> Diario El Clarín, 09/09/2004]

c. Condoleezza Rice, la asesora de seguridad nacional de Bush, dijo a su vez que «de hecho esperamos que Chávez reconozca que el mundo entero está observando, y que aproveche esta oportunidad para enderezar su barco, que se ha estado moviendo, sinceramente, en la dirección equivocada por un buen tiempo». [RAE: Banco de datos (CREA) Corpus de referencia del español actual. $<$ http://www.rae.es $>$ La Prensa de Nicaragua, 15/04/2002]

En estos ejemplos que acabamos de presentar, la presencia de los rasgos que contiene la base adjetiva se hacen evidentes en la interpretación del adverbio; sin embargo, el adverbio hace mucho más, pues, como también vimos que ocurría en los adverbios de dominio, la presencia del sufijo adverbial permite ampliar las posibilidades de alcance e interpretación del adverbio, no contenidas en el adjetivo base. En concreto, el adverbio de manera de hablar no solo define al hablante sino que se utiliza como marca discursiva para dirigirse a un oyente o lector y exponer una opinión.

En el ejemplo de (18a), el adverbio francamente acompaña a un verbo de opinión: Yo creo que no, francamente creo que no. El adverbio relaciona al hablante con su afirmación. Frente a los ejemplos anteriores, aquí, el adverbio no se limita a definir al hablante como franco ante lo que dice: 'Yo soy franco al decir que creo que no'; en este entorno, el hablante define su opinión como franca: 'Yo opino que no y esta es una opinión franca, sincera'. Por tanto, la paráfrasis típica de los adverbios de la manera del decir resulta inapropiada para captar el significado que posee el adverbio y su relación con el fragmento en el que se inserta. Se parte de los rasgos que posee la base adjetiva para utilizarlos como un modo de presentación no del propio hablante sino de su opinión. Este punto de vista se ofrece al oyente-lector con la garantía de la franqueza. Así pues, es la afirmación que realiza el hablante, su contenido, el que se ve calificado por el adverbio y presentado de este modo ante el oyente-lector.

En los ejemplos de (18b y c) no existe un verbo de opinión realizado, pero sí se puede deducir del discurso. En (18b), el adverbio honestamente tiene alcance sobre la afirmación: yo tengo mis temores. Esta afirmación se presenta como un juicio del hablante sobre los hechos que relata: '(el enfermo) va y viene de la clínica, (esto no es bueno) y por ello yo tengo mis temores'. La opinión del hablante se presenta, de nuevo, como honesta.

Fijémonos ahora en (18c): su barco, que se ha estado moviendo, sinceramente, en la dirección equivocada por un buen tiempo. En este ejemplo, se parte de los rasgos lingüísticos de la base adjetiva: sincero. Pero el hablante no se presenta simplemente como sincero ante lo que dice: 'Soy sincero al decir que (el) barco se ha movido en la dirección equivocada'. La presencia del adverbio es una llamada de atención discursiva dirigida al lector. Lo que se afirma es una opinión del hablante. La afirmación contenida en el párrafo aparece expuesta desde el punto de vista del hablante, que nos da su opinión justificada con garantías de credibilidad al oyente-lector, pues se presenta bajo las características de la sinceridad. Por tanto, en este contexto, el adverbio de la manera del decir no sirve para que el hablante se defina o presente: 'soy sincero al decir que...', sino que se utiliza presentar y justificar una determinada opinión bajo la etiqueta de la sinceridad: 'Yo opino que (ese) barco se está moviendo en la dirección equivocada y esto lo digo de manera sincera'. 
En todos estos ejemplos se hace evidente que el adverbio no es solo una marca presentadora de la actitud del hablante; su presencia califica la afirmación que realiza el hablante $-\mathrm{y}$ que sirve para presentarlo de modo indirecto a través de ella-. En consecuencia, según estos nuevos datos, el adverbio relaciona al hablante, su opinión presentada de una determinada manera, y al receptor, que es el que debe interpretar dicha opinión según las claves que le ofrece el hablante. La posibilidad de incorporar la opinión del hablante parece depender del contexto en el que se inserta el adverbio.

\section{La conjunción que enunciativa}

En el caso de los adverbios, la manifestación del habla se realiza de manera indirecta; esto quiere decir que, a excepción del propio adverbio, no existe ningún otro índice en la oración que remita al hecho concreto de habla. En el ejemplo de (19a), en cambio, la presencia del habla se manifiesta de manera directa a través de una conjunción opcional y del propio verbo de habla.

(19) a. ¿Qué me has dicho? (Que) digo que estoy contento de verte.

b. Llanamente (Te digo llanamente que) no me gusta tu comportamiento.

El que enunciativo es otra manera de expresión del habla o de la manera del decir, localizado también en la periferia oracional izquierda de la oración. Aunque su proyección no es obligatoria para asegurar la gramaticalidad de la secuencia, su presencia conlleva una interpretación determinada y, además, puede desencadenar ciertos fenómenos de tipo sintáctico en la oración. La conjunción que, como se recoge en Porroche (2000), Pons (2003) y Rodríguez Ramalle (2008), entre otros trabajos, puede introducir un discurso nuevo, puede hacer referencia a un discurso anterior, que es repetido al ser introducido por la conjunción con el fin de reiterarlo y enfatizarlo; asimismo, al introducir un discurso, puede servir para referirse a un contexto previo, basado ahora en los conocimientos compartidos por los hablantes. Estos tres tipos de lecturas aparecen recogidas en los datos que reproducimos seguidamente:

(20) a. ¿Qué hora es ya? Son la... ¿te tienes que ir ya? La una. Pues anda, que hoy nos hemos pasado. [RAE: Banco de datos (CREA) Corpus de referencia del español actual. $<$ http://www.rae.es> Oral]

b. «Bueno, venga, que se queden»... Te da pena, te da cosa... ¿sabes?, pero que tuve una guerra que me que me puso..., que entre el dolor que tenía del... de cabeza del examen y luego los nervios de los niños yo estaba todo el rato: «¡Dios mío!, ipero cuándo se irán al colegio!» [RAE: Banco de datos (CREA) Corpus de referencia del español actual. $<$ http://www.rae.es $>$ Oral]

En los ejemplos de (20), la presencia del que no parece remitir a nada dicho o expresado con anterioridad. Esto significa que la oración introducida por la conjunción es independiente del discurso o situación previa. El valor que encontramos en estos datos es el de simple introductor del discurso: la conjunción sirve para apoyar lo que se dice o afirma.

(21) a. - ¿Puedes leer la hora en mi reloj? -insistió

¡Este niño debía imaginarse que era totalmente analfabeto! 
- ¿Que si puedo leer la hora en un reloj digital? Claro que puedo -dije con cierto orgu1lo- [RAE: Banco de datos (CREA) Corpus de referencia del español actual. <http:// www.rae.es>]

b. Usted será, claro, por la edad, primo de Pichuca Zamacois!»

«iQue no, mujer, cómo va a ser primo de Pichuca si Pichuca es de nuestra edad!...» [RAE: Banco de datos (CREA) Corpus de referencia del español actual. $<$ http://www.rae.es $>$ ]

En el ejemplo de (21a) la pregunta: ¿Que si puedo leer la hora en un reloj digital? remite a una pregunta emitida por el entrevistador, incorporando un valor modal de sorpresa y enfado, matices que no son extraños de encontrar en los usos repetitivos del que. En el ejemplo de (21b), la conjunción que introduce una negación que sirve para contradecir lo expresado anteriormente: ¿Que no, mujer, cómo va a ser primo de Pichuca si Pichuca es de nuestra edad! En este caso, no se repite el discurso anterior de manera literal, pues se retoma para ser negado. Es precisamente la base lingüística previa: Usted será, claro, por la edad, primo de Pichuca Zamacois y su manifestación en la nueva oración introducida por el que, la que refuerza la negación y el carácter enfático de ésta por contraste con la afirmación anterior.

(22) a. Pues, oye, Luisa, que la hija de los vecinos de arriba se casa

b. Que he oído que han cortado el tráfico por la fuerte nevada.

En estas oraciones, la presencia de la conjunción implica que el hablante comunica una información que ha conocido por medios diversos: se la han dicho, la ha visto, etc. Lo relevante es que el hablante ejerce de transmisor de una información que repite a su interlocutor. La marca que aparece para indicarnos que tal información ha sido oída o comunicada previamente, esto es, que se repite, es la conjunción que.

Pero, además de estos rasgos semánticos en los que la presencia de un discurso previo determina la interpretación del que enunciativo, vemos que la proyección de esta conjunción en el margen preverbal puede ampliar la estructura izquierda de la oración. Fijémonos en los siguientes datos:

(23) a. Que digo yo que podríamos empezar a cenar hoy.

b. Que dice el jefe que nos pongamos a trabajar ahora mismo.

c. Que pregunta Pedro que quién va a venir.

d. A oídos de las Cano esto resultó ser aún más admirable quizás que lo anterior, así que una de ellas exclamó: «iAh, pero no importa lo más mínimo!»Y la otra comentó: «Que digo yo que nos darán en esta casa un té, una copa, un algo. Son pasadas ya las seis. [RAE: Banco de datos (CREA) Corpus de referencia del español actual. $<$ http:// www.rae.es $>$ Oral]

En estos ejemplos, la conjunción aparece seguida de un verbo de habla y un sujeto pospuesto. Si nos fijamos en las oraciones recogidas en (23), es fácil comprobar que si eliminamos la conjunción y la secuencia del verbo de habla: que digo yo, que dice el jefe, el segundo que actúa como introductor de la oración subordinada, sin merma de la gramaticalidad de las secuencias: Que podríamos empezar hoy, Que nos pongamos a trabajar ahora mismo.

Cuando el que se proyecta en una oración hace que la estructura final sea más compleja, pues puede llegar a incluir incluso un verbo de habla con sus modificadores, y un sujeto 
nuevo. Esta nueva estructura forma parte de la manera del decir: es una estructura que no siempre se hace visible en español y que extiende, al proyectarse, la construcción de la oración previamente constituida. Así como en la configuración habitual de una oración encontramos adverbios, un sujeto, un verbo y sus modificadores y complementos, también en la proyección extendida, manifestación sintáctica del habla, podemos tener adverbios de la manera del decir, un sujeto, un verbo y modificadores: Que, sinceramente, digo yo que podríamos empezar a cenar hoy. Sinceramente, que digo yo que podríamos empezar a cenar hoy.

\section{La estructura funcional de la periferia izquierda de la oración}

\subsection{Bases teóricas}

Las propuestas actuales que analizan los fenómenos que tienen lugar en el margen izquierdo de la oración parten de los trabajos de Rizzi (1997 y 2004) y Belletti (2004), comentados en la sección 2., para incluir una estructura ampliada enriquecida con la inclusión de una proyección funcional cuyo cometido es relacionar la estructura de la oración con el discurso. Speas y Tenny (2003) proponen tratar de manera separada la interfaz léxico-sintaxis de la interfaz pragmática-sintaxis. Con este objetivo, defienden la existencia de una proyección especial que tomaría como complemento a la proyección sintáctica superior y cuyo cometido sería representar en la sintaxis la información pragmática contenida en todo acto de habla. Dicha información pragmática estaría representada por un conjunto de papeles-pragmáticos, distintos de los temáticos saturados en el Sintagma Verbal; los papeles-pragmáticos se saturarían igual que los papeles-temáticos, pero no en el dominio del SV, sino en la proyección funcional superior vinculada con el hecho de hablar y que las autoras denominan Speech Act Phrase (SAP) y que se organiza en dos niveles: SAP y SAP*, más interno. Dentro de estos dos nieves se saturarían los papeles-pragmáticos hablante, oyente y contenido de la oración: el hablante sería el agente o argumento externo, especificador del SAP superior; por su parte, el oyente sería la meta u objetivo del acto de habla, generado como complemento del SAP inferior; mientras que el contenido ocuparía la posición de especificador del SAP inferior, como si fuera el tema de la predicación. La combinación de estos papeles temáticos darán los diferentes tipos de acto de habla de una oración:

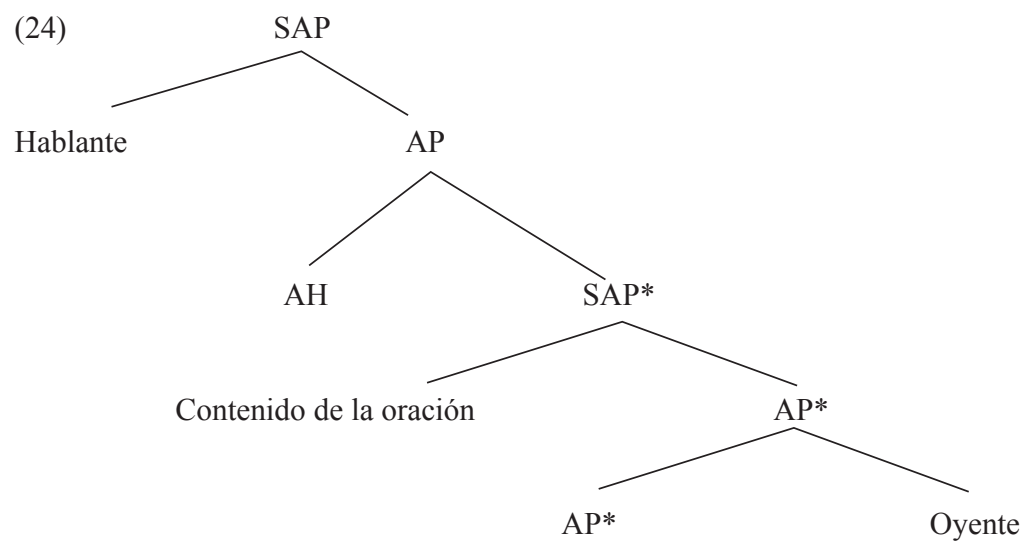


Para nuestra explicación seguiremos esta propuesta de estructura, en la que aparecen incluidos el hablante o fuente de la información, el oyente y el contenido de la oración. Estos tres elementos intervienen, como hemos visto, en la interpretación que reciben las tres estructuras aquí revisadas: adverbios de dominio, de la manera del decir y el que enunciativo.

\subsection{Combinaciones posibles y relación entre las estructuras}

Dado que la interpretación está vinculada con la posición que ocupan los constituyentes estudiados en la periferia izquierda de la oración, a continuación me propongo partir de la estructura funcional discursiva ampliada para ubicar y explicar la posición de dichos constituyentes.

Los adverbios de la manera del decir no se limitan a presentar o definir al hablante como responsable de lo que dice: 'soy sincero, franco, honesto cuando digo o afirmo que...'. Estos adverbios pueden además servir para presentar y justificar una determinada opinión bajo la etiqueta de la sinceridad, la franqueza o la honestidad. En consecuencia, según estos nuevos rasgos, el adverbio vincula al hablante y su opinión, presentada de una determinada manera, con el receptor, que es el que debe interpretar dicha opinión. Por tanto, dentro de la periferia izquierda de la oración, estos adverbios deben situarse en aquellas posiciones en las que puedan relacionar al hablante, a su afirmación y al oyente. Dicha posición parece ser, dada la estructura de (24), la de especificador del sintagma SAP, vinculado con la expresión del hablante; en dicha posición, los adverbios tienen además alcance sobre el hablante, el contenido de la oración y el oyente:

(25) $\left[_{\mathrm{SAP}}\right.$ Francamente $\left[_{\mathrm{AP}}\left[\left[_{\mathrm{SAP} *}\right.\right.\right.$ contenido de la oración $\left[\left[_{\mathrm{AP} *}\right.\right.$ oyente $\left.\left.\left.]\right]\right]\right]$

Para justificar esta ubicación, debemos fijarnos en más datos. La conjunción que en los ejemplos que hemos analizado a partir de los datos de (20), (21), (22) y (23) tiene la posibilidad de referirse a un discurso previo o bien de hacer visible una estructura extendida del margen izquierdo. En una oración como Que digo yo que podríamos irnos ya, no existe en términos estrictos una situación o discurso previo. Si prestamos atención, nos daremos cuenta de que el hablante se hace visible a través del que: es la propia conjunción la que indica la existencia de un hablante que comienza su emisión y que se manifiesta en la estructura sintáctica. La propuesta es que, en estos casos, la situación previa que lleva a la emisión de este enunciado está codificada en una estructura como la de (26), en la que la conjunción que se sitúa en el núcleo del primer SAP. Dicha proyección selecciona como su complemento un segundo nivel SAH*, en cuyo núcleo se sitúa el verbo de habla:

(26) $\left[_{\mathrm{SAP}}\right.$ Francamente $\left[_{\mathrm{AP}}\right.$ que $\left[_{\mathrm{SAH}^{*}}\left[_{\mathrm{AH}}\right.\right.$ digo $\left[_{\mathrm{SComp}}\right.$ yo $\left[_{\mathrm{Comp}}\right.$ que $\left[_{\mathrm{STiempo}} \ldots\right.$ podríamos ir ya]]]]

Nótese que mientras que el que se sitúa en el núcleo del sintagma, los adverbios de la manera del decir se sitúan como especificadores de esta proyección, pues podemos tener secuencias del tipo:

(27) a. Francamente, que digo yo que podríamos irnos ya.

b. Honestamente, que creo que deberíamos decir lo que sucedió realmente. 
La posibilidad de cambiar el orden es posible, pero con algunas restricciones, pues parece depender del sujeto y del tipo de adverbio:

(28) a. Que, francamente, digo yo que podríamos irnos ya.

b. (??) Que, sinceramente, dice el jefe que nos pongamos a trabajar ya.

c. Que, en pocas palabras, terminemos de una vez.

Nótese que la expresión de (28c) no caracteriza ni al hablante ni al discurso: es expresión de la manera verbal. Dicho de otro modo, la paráfrasis de esta expresión excluye siempre al sujeto responsable de la manera de hablar, para poner el énfasis en la manera: 'digo en pocas palabras que terminemos de una vez'.

Los adverbios de dominio con alcance oracional pueden llevar la presencia del gerundio hablando en posición pospuesta, como podemos ver en los siguientes ejemplos:

(29) a. La actual alcaldesa, María del Carmen Guijorro (PP), calificó de «incoherente» el acuerdo de Gobierno entre PSOE e IU, ya que «se han llamado sinvergüenzas, Tamayos, se han acusado de cohecho, se han interpuesto querellas criminales mutuamente... y ahora se meten en la misma cama, políticamente hablando, por la ambición de ocupar el sillón del poder». [RAE: Banco de datos (CREA) Corpus de referencia del español actual. <http://www.rae.es> La Razón Digital, 16/12/2003]

b. Musicalmente hablando, se puede decir que Bruselas es una ciudad muy fuerte.

Estos datos muestran que el adverbio de dominio modifica directamente a un verbo de habla: politicamente hablando, musicalmente hablando. Según la hipótesis aquí expuesta, y de acuerdo con la estructura de (24), este verbo de habla, que puede manifestarse explícitamente en estructuras especiales: Que digo yo que..., ocupa la posición de núcleo del nivel más interno del SAP*, aquel que está vinculado con la expresión del contenido. A su vez, los adverbios de dominio se situarían en el especificador de dicha proyección, en una estructura similar a la siguiente:

(30) $\left[_{\mathrm{SAP}}\left[{ }_{\mathrm{SP}}\right.\right.$ Que $\left[\left[_{\mathrm{SAP}}\right.\right.$ políticamente $\left[\left[_{\mathrm{AP}^{*}}\right.\right.$ hablando $\left.\left.\left.\ldots\right]\right]\right]$

Tal y como predice la estructura, los adverbios de dominio también pueden situarse entre la conjunción y el verbo de habla, pero no pueden ubicarse delante de la conjunción que, pues esta marca se relaciona con la proyección SAP superior, expresión del hablante:

(31) a. Que, políticamente (hablando), hacer eso sería como compartir la misma cama.

b. *Moralmente (hablando), que no me parece un comportamiento correcto.

Según lo dicho, la estructura final quedaría del siguiente modo (el contenido semántico asociado a las proyecciones aparece entre paréntesis):

En esta configuración, los diferentes constituyentes que hemos analizado ocupan una posición en la estructura discursiva de la oración dependiendo de su interpretación. Así, los adverbios orientados al hablante de la manera del decir se relacionan con la proyección vinculada con el hablante; en esta misma proyección, hemos situado al que enunciativo introducir del discurso. En los que respecta a los adverbios de dominio, estos tienen alcance sobre el 
contenido de la oración, por lo que se vinculan con la proyección asociada tanto al contenido como al oyente; en el núcleo de esta misma proyección hemos situado a los verbos de habla que se manifiestan explícitamente con la conjunción que (Que digo yo que podríamos salir a tomar algo), y con los adverbios de dominio (Gramaticalmente hablando, esta oración es incorrecta).

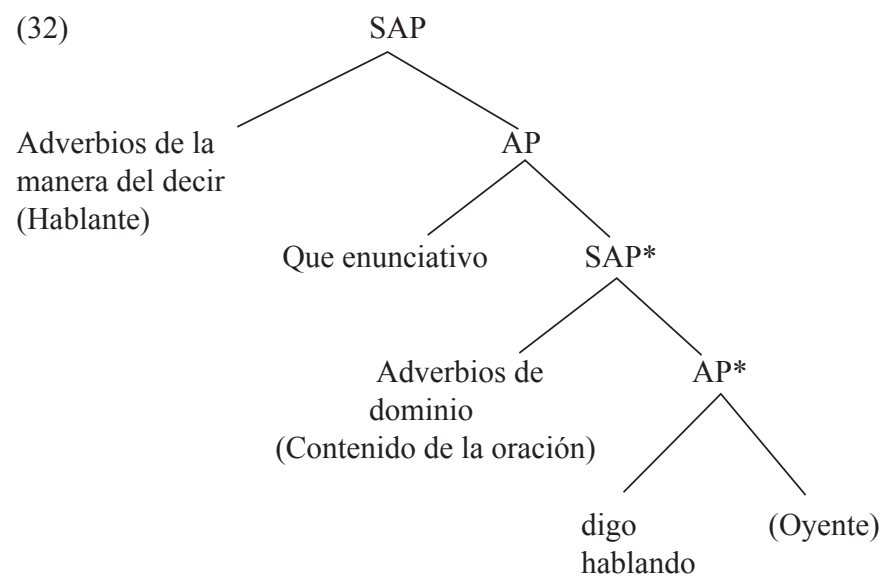

\section{7. ¿Qué ocurre en la modificación adjetiva?}

Corver (1997a y b) propone un estudio de la estructura interna del S(intagma) Adj(etivo). Resumidamente, su propuesta se puede explicar de la siguiente manera. Dentro del SAdj podemos distinguir dos tipos diferentes de proyecciones funcionales: un S(intagma) Grado y un Sintagma Cuantificador - al que designaré a partir de ahora con el nombre de S(intagma) Q-. Los núcleos de ambas proyecciones pueden estar ocupados por palabras de grado que van a actuar como operadores. Así, el núcleo Grado estará ocupado por palabras de grado cuyo comportamiento se puede relacionar con el de los determinantes (too, how, as, en inglés; tan, en español) -oración de (33a)-, mientras que en el núcleo Q aparecerán aquellos constituyentes que actúen de manera similar a los cuantificadores (much, little, enough, en inglés; más, menos, en español) -ejemplo de (33b)-.

(33) a. María es tan alta como Juan.

b. María es \{más /menos\} alta que Juan.

c. $\left[_{\text {SGrado }}\left[{ }_{\text {Grado }} \tan \left[{ }_{\mathrm{SQ}}\left[\mathrm{Q}, \operatorname{más} / \operatorname{menos}\left[{ }_{\mathrm{SAdj}}\right]\right]\right]\right]\right]$

Los diferentes tipos de operadores de grado ligan una variable de Grado contenida en la estructura argumental de los adjetivos graduales. De este modo un adjetivo como alto poseería la siguiente entrada léxica $<1, \mathrm{G}>$, donde el número 1 remite al argumento que toma el adjetivo: Juan, árbol, etc., mientras que $\mathrm{G}$ es una variable ligada por el operador de grado -Corver (1997a: 131): 


$$
\begin{aligned}
& \text { (34) a. Alto }<1, G> \\
& \text { b. }\left[_{\text {SGrado }} \tan _{\mathrm{i}}\left[{ }_{\mathrm{SQ}} \text { alto }_{<1, \mathrm{Gi}>\mathrm{k}}\left[\left[_{\mathrm{SAdj}} \mathrm{h}_{\mathrm{k}}\right]\right]\right]^{3}\right.
\end{aligned}
$$

En Rodríguez Ramalle (2003) se propone que los adverbios de dominio pueden situarse delante del resto de modificadores, pues tienen un alcance mayor: por este motivo, se generan como especificadores del SGrado. En tanto que operadores, tales adverbios establecen las condiciones de verdad dentro de las cuales debe ser interpretada la relación entre el adjetivo y su argumento. Así, por ejemplo, en una oración como la siguiente: Es algo lógico económicamente porque el consumidor se queda mucho más tranquilo se dice que es algo lógico pero desde un punto de vista económico, esto es, que es verdad la relación entre el adjetivo económico $<1>$ y su argumento $<1>$ en el dominio del operador económicamente. Recuérdese, sin embargo, que la relación entre estos adverbios y el adjetivo puede estar influida por aspectos discursivos y extralingüísticos, tal y como hemos justificado, por lo que el adverbio, si bien se genera en el dominio funcional que proyecta el adjetivo, se vincula con el discurso, al igual que ocurre cuando tiene alcance oracional.

\section{Conclusiones}

La propuesta actual de estructura funcional extendida en la que se codifica gramaticalmente la existencia de una categoría relacionada con el hablante, el contenido de la oración y el oyente permite incluir y tratar ciertos fenómenos que ocurren en la periferia izquierda de la oración. Tomando como excusa dicha estructura extendida, hemos analizado la importancia que adquieren los aspectos lingüísticos y extralingüísticos en la interpretación de los adverbios de punto de vista, los adverbios de la manera del decir y la conjunción que como marca enunciativa.

En el caso de los adverbios de dominio hemos visto que en su interpretación intervienen aspectos exclusivamente lingüísticos, a saber: las propiedades semánticas derivadas de la base adjetiva, junto con otros factores tales como el conocimiento que poseen los hablantes acerca de la realidad, o la información contenida en el discurso. En el caso de los adverbios orientados al hablante de la manera del decir, las bases adjetivas nos dan información acerca

3 El adverbio francamente también puede incidir sobre adjetivos, según vemos en los siguientes datos:

(i) a. A Edward Norton le acaban de decir que después de todas las entrevistas que ha concedido, todavía le queda una rueda de prensa con periodistas extranjeros para promocionar su última película, El dragón rojo. Es un comentario inesperado de un actor adicto a personajes violentos, marginales o psicópatas y con fama de exigente, perfeccionista, e incluso de ser alguien francamente difícil. [RAE: Banco de datos (CREA) Corpus de referencia del español actual. <http://www.rae.es> El País. El País de las Tentaciones, 18/10/2002]

b. P. El matrimonio de la Razón y la Miseria es el título que le han dado a su interpretación de la obra de Goya. ¿Puede el arte contemporáneo ofrecer alguna solución en un mundo donde la razón apenas existe y la miseria nos supera? R. Es que no es ésa la relación que queremos establecer entre razón y miseria. La razón es absolutamente contigua a la miseria. Como usted insinúa en su pregunta, la razón es un valor imperialista con un impacto virulento global que contiene conceptos francamente mal analizados, como puede ser el de «democracia». [RAE: Banco de datos (CREA) Corpus de referencia del español actual. <http://www.rae.es> El País. Babelia, 24/04/2004]

Nótese, no obstante, que en este uso el adverbio francamente tiene una interpretación gradativa, frente a lo que ocurre con los adverbios de dominio, que cuando inciden solo sobre el adjetivo no adquieren un valor diferente. Podemos decir, por tanto, que en este caso, francamente ha perdido la posibilidad de orientarse al hablante y de adquirir rasgos discursivos. 
de la posibilidad de predicarse del individuo y de la acción que realiza; pero la interpretación final de estas unidades no se queda aquí, pues el contexto favorece que sean utilizadas como marcas para la expresión de la opinión del hablante. Por último, la conjunción que, cuando introduce el discurso, puede desencadenar fenómenos sintácticos tales como la posposición del sujeto y la presencia de un verbo de habla explícito; estos hechos nos dan pistas acerca de las estructuras sintácticas que se proyectan en el margen izquierdo de la oración.

\section{Referencias bibliográficas}

Belletti, A. (2004): «Aspects of the Low IP Area». En Rizzi, L. (ed.): The Structure of CP and IP. The Cartography of Syntactic Structures, (volumen 2). Oxford, OUP, págs. 16-51.

Bosque, I. (1993): «Sobre las diferencias entre los adjetivos relacionales y los calificativos», Revista Argentina de Lingüística, 9, págs. 9-48.

Bosque, I. (1999): «El sintagma adjetival. Modificadores y complementos del adjetivo. Adjetivo y participio». En Bosque, I. y V. Demonte I (coords.): Gramática descriptiva de la lengua española. Madrid, RAE (colección Nebrija y Bello)-Espasa Calpe, capítulo 4, págs. 217-310.

Cinque, G. (1999): Adverbs and Functional Heads. A Crosslinguistic Perspective. Oxford University Press, Oxford.

Corver, N. (1997a): «Much-support as a Last Resort», Linguistic Inquiry, 28, págs. 119-164.

Corver, N. (1997b): «The Internal Syntax of the Dutch Extended Adjectival Projection», Natural Language and Linguistic Theory, 15, 2, págs.289-368.

Demonte, V. (1999): «Semántica composicional y gramática. Los adjetivos en la interficie léxico-sintaxis», RSEL 29, 2, págs. 283-316.

Fábregas, A. (2007): «The internal syntactic structures of relational adjectives», Probus, 19, págs.1-36.

Hernanz, Ma. L. Y J. Ma . Brucart (1987): La sintaxis. Principios teóricos. La oración simple, Madrid, Crítica.

Pons Bordería, S. (2003): «Que inicial átono como marca de modalidad», ELUA, 17; págs. 531-545.

Porroche, M. (2000): «Algunos aspectos del uso de que en el español conversacional (que como introductor de oraciones 'independientes'», CLAC, 3, 2000.

Rizzi, L. (1997): «The Fine Structure of the Left Periphery». En Haegeman L. (ed.): Elements of Grammar. Amsterdam, Kluwer Academic, págs. 281-337.

Rizzi, L. (2004): «Locality and left periphery». En Belletti, A. (ed.): Structures and Beyond. The Cartography of Syntactic Structures, vol. 3. Nueva York, Oxford University Press, págs. 281-339.

Rodríguez Ramalle, T. M. (1999) Algunos aspectos de la sintaxis y semántica de los adverbios y de las construcciones adverbiales. Tesis doctoral, Universidad Autónoma de Madrid.

Rodríguez Ramalle, T. M. (2003): La gramática de los adverbios en -mente o cómo expresar maneras, opiniones y actitudes a través de la lengua. Madrid, Publicaciones de la Universidad Autónoma de Madrid.

Rodríguez Ramalle, T. M. (2008): «Estudio sintáctico y discursivo de algunas estructuras enunciativas y citativas del español», Revista Española de Lingüistica Aplicada, 21, págs. 269-288.

Rodríguez Ramalle, T. M. (en prensa): Sobre lo politicamente correcto: algunas claves para interpretar los adverbios de dominio en prensa, en Lengua, literatura y medios de comunicación. Homenaje a Pilar Palomo. Universidad Complutense de Madrid.

Speas, M. y C. Tenny (2003): «Configurational properties of point of view roles». En Di Sciullo, A. M. (ed.): Asymmetry in Grammar. Amsterdam, John Benjamins, págs. 315-344. 